\title{
ANNULATA EVENT Z PROFILU V JÁMOVÉM LŮMKU U OCHOZI U BRNA - POZNÁMKY KE KONODONTOVÉ BIOSTRATIGRAFII (FAMEN, MORAVSKÝ KRAS)
}

\author{
Annulata event from a pit-quarry near Ochoz u Brna - remarks on conodont biostratigraphy \\ (Famennian, Moravian Karst)
}

\author{
Tomáš Weiner, Jiří Kalvoda \\ Ústav geologických věd PřF MU, Kotlářská 2, 61137 Brno; e-mail: tomasweiner@volny.cz
}

(24-41 Vyškov)

Key words: Moravian Karst, Famennian, Annulata event, Líšeň Formation, conodont biostratigraphy

\begin{abstract}
About two meters thick section of the Famennian Křtiny Limestones (Lišeň Formation) was studied in a small pit-quarry near the road leading from Brno-Líšen to Ochoz u Brna. Conodont samples were taken from seven different stratigraphical levels. A richly fossiliferous interval (about $40 \mathrm{~cm}$ thick) can be distinguished in the higher part of the section. This interval is characterized by abundant occurence of clymenids, bivalves, orthocone nautiloids, trilobites and other groups. Black limestone lenses (maximal thickness about $10 \mathrm{~cm}$ ) are developed in the lowermost part of the richly fossiliferous interval. A presence of Palmatolepis glabra lepta (late morphotype), Palmatolepis minuta minuta and Palmatolepis rugosa trachytera suggests these black limestones probably represent the Lower Annulata event (Upper Palmatolepis rugosa trachytera zone). Polygnathus styriacus indicating the base of the Palmatolepis perlobata postera zone enters within about 10 centimeters thick interval of dark grey biodetritic limestones which occur closely above the black limestone lenses. The Upper Annulata event and equivalents of „Wagnerbank"or „Annulata limestone" were not distinguished in the studied section. This might be caused by condensed sedimentation. Grey limestones and marly limestones belonging to the higher part of the richly fossiliferous interval are placed above the base of the Palmatolepis perlobata postera zone. The studied locality might correspond to the original fossil site described by Rzehak in 1910.
\end{abstract}

Úvod

Globálně rozšířené střednofamenské annulata eventy bývají spojovány s krátkodobým interglaciálním vzestupem úrovně mořské hladiny, který přerušil celkové trendy regrese a postupné ochlazování klimatu (Sandberg et al. 2002, Joachimski et al. 2009). Vyznačují se polohami tmavě šedých až černých anoxických nebo hypoxických sedimentů, které často obsahují hojnou makrofaunu složenou zejména $\mathrm{z}$ ammonoidů, mlžů, ortokonních nautiloidů a ostrakodů (viz např. Walliser 1996). Annulata eventy stratigraficky spadají na bázi cephalopodové zóny Platyclymenia annulata (UD IV-A sensu Becker - House 2000). Korelace s konodontovou zonací byla delší dobu interpretována nejednotně. Předchozí autoři zařazovali annulata eventy do svrchní ćásti zóny Palmatolepis rugosa trachytera (např. Walliser 1996, Raczka et al. 2010), kolem rozhraní zón Palmatolepis rugosa trachytera a Palmatolepis perlobata postera (House 2002) a do zóny spodní Palmatolepis perlobata postera (např. Korn - Ziegler 2002, Clausen - Korn 2008). Podle nejnovějších závěrů Hartenfelse (2011), který studoval detailně vzorkované profily z Německa (Rýnský masiv, saxothuringikum), Polska (Svatokřrižské hory) a jv. Maroka, náleží spodní a svrchní annulata eventy do zóny svrchní Palmatolepis rugosa trachytera. Do téže zóny zařadil i nadložní polohy slínovce „Wagnerbank“ a jeho ekvivalenty (např. „Annulata“ limestone) (viz obr. 1). Na profilech může být vyvinuta jedna nebo více poloh (zpravidla dvě) černých vápenců nebo břidlic annulata eventů (např. Walliser 1996, Korn 2004, Raczka et al. 2009, Hartenfels 2011). Z Moravského krasu

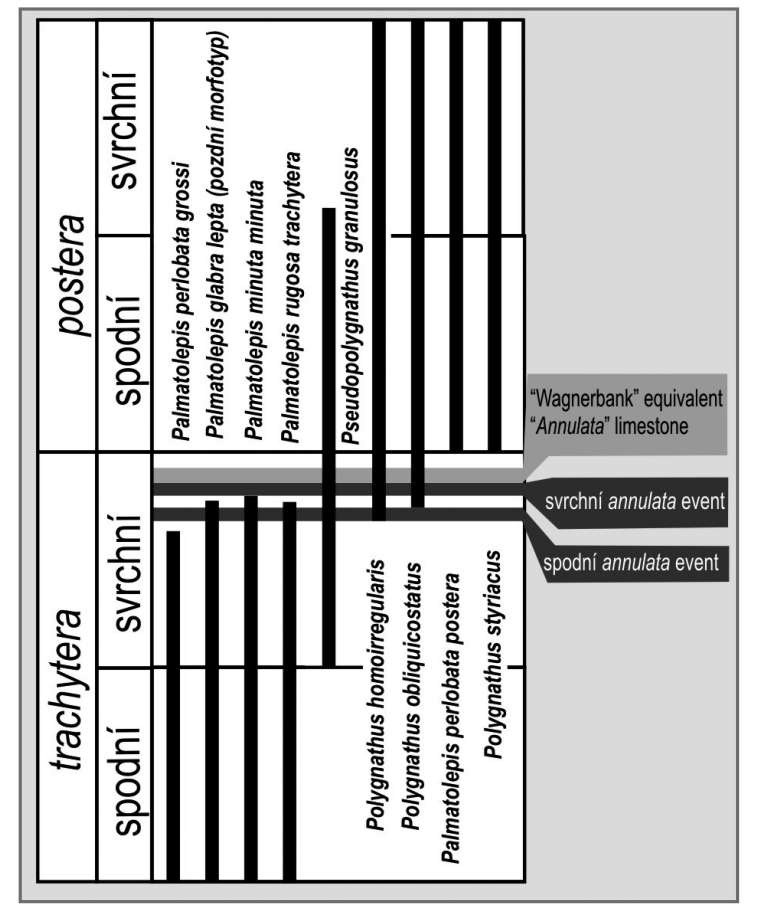

Obr. 1: Stratigrafické rozsahy vybraných konodontových taxonů v rámci konodontových zón Palmatolepis rugosa trachytera („,trachytera“) a Palmatolepis perlobata postera („postera“) vztažených $\mathrm{k}$ annulata eventům. Upraveno podle Hartenfelse (2011).

Fig. 1: Stratigraphic ranges of selected conodont taxa around the Annulata events within the Palmatolepis rugosa trachytera („trachytera“) and Palmatolepis perlobata postera („postera“) conodont zones. Modified after Hartenfels (2011). 


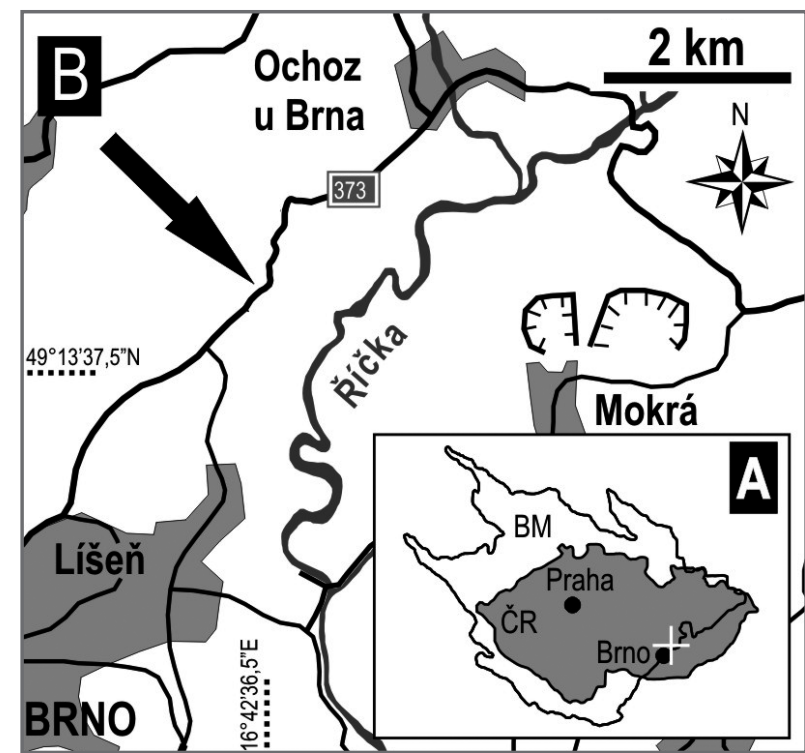

Obr. 2: A - poloha studované lokality (bílý křrižek) v rámci České republiky (ČR) a Českého masivu (BM); B - poloha studované lokality (šipka) v jižní části Moravského krasu.

Fig. 2: A - Geographic position of the studied locality (marked by white cross) in the southeast part of the Czech Republic ( $\check{C} R)$ and Bohemian Massif (BM); B - Geographic position of the new locality (marked by arrow) in the south part of the Moravian Karst.

byly polohy odpovídající annulata eventu dosud popsány z oblasti mezi Ochozí u Brna a Brnem-Líšní (Rzehak 1910) a z lomu Mokrá (Dvořák et al. 1988). V roce 2009 byly T. Viktorýnem zjištěny čočky černých vápenců $\mathrm{v}$ jámovém lůmku situovaném při západním okraji silnice $\mathrm{z}$ Brna-Líšně do Ochozi u Brna (obr. 2). Vzhledem k prŕitomnosti odpovídající makrofauny, zejména akumulací typických ammonoidů včetně vůdčího taxonu Platyclymenia annulata MÜNSTER, i litologické totožnosti materiálu je pravděpodobné, že by se mohlo jednat právě o lokalitu popsanou Rzehakem (1910). Ten zřejmě nedopatřením uvedl chybnou lokalizaci, podle které by lokalita měla být situována severněji v oblasti výskytu devonských bazálních klastik, na což upozornil již Chlupáč (1966).

\section{Metodika}

Na profilu odkrytém ve zmíněném jámovém lůmku byla makroskopicky popsána litologie, která je znázorněna v litologickém schématu (obr. 3). Následně byly odebrány vzorky vápenců ze sedmi úrovní, které byly dále macerovány v cca $15 \%$ roztoku kyseliny octové. $Z$ nerozpustného zbytku byly konodontové elementy manuálně separovány a následně determinovány. V článku je použita standardní konodontová zonace sensu Ziegler - Sandberg (1984).

\section{Popis profilu}

Odkrytý sled o mocnosti cca 2 m (obr. 3) je tvořen převážně šedými křtinskými vápenci. Přibližně v rozmezí mocnosti 1,3 až $1,7 \mathrm{~m}$ nad bází profilu je vyvinut interval $s$ hojnou makrofaunou. Jeho nejnižší část tvoří horizont černých čočkovitých „klymeniových“ vápenců (obr. 3, poloha A) o maximální mocnosti 10 až $15 \mathrm{~cm}$ s četnou faunou

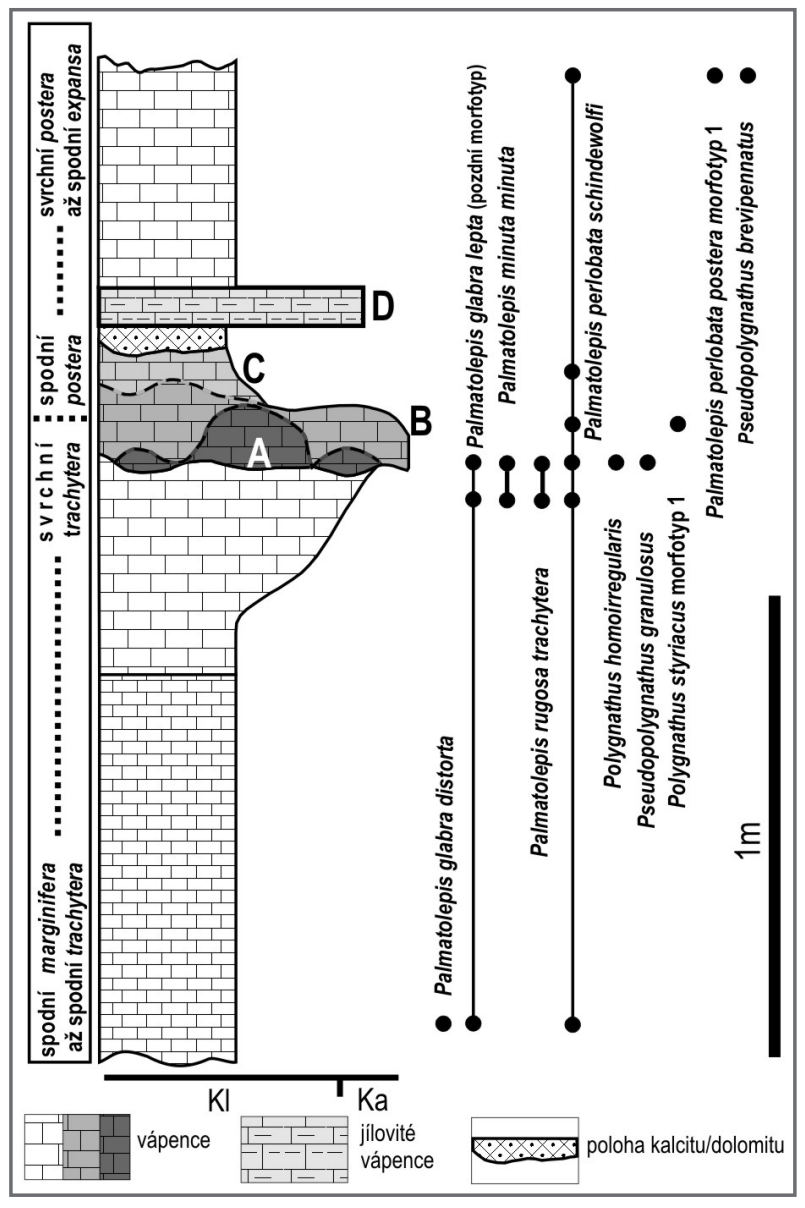

Obr. 3: Litologické schéma studovaného profilu, zjištěné stratigrafické rozsahy vybraných konodontových taxonů a konodontová zonace (sensu Ziegler - Sandberg 1984). Zkratky: Kl - kalcilutit, $\mathrm{Ka}$ - kalciarenit.

Fig. 3: Lithological scheme of studied section, stratigraphic ranges of selected conodont taxa and standard conodont zonation (sensu Ziegler - Sandberg 1984). Abbreviations: Kl - calcilutite, $\mathrm{Ka}$ - calcarenite.

klymenií (zejména Platyclymenia), epiplanktonních mlžů (Guerichia), goniatitů a dalších skupin. Při svrchní části čoček černých vápenců je nesouvisle vyvinuta cca $1 \mathrm{~cm}$ mocná poloha vyznačující se akumulací makroskopicky nedeterminovatelných fragmentů schránek (ve schématu na obr. 3 byla tato poloha zanedbána). Směrem do nadloží je vyvinuta poloha tmavěji šedého biodetritického vápence (obr. 3, poloha B), která rovněž obsahuje relativně četnou makrofaunu složenou $\mathrm{z}$ ammonoidů, ortokonních nautiloidů, mlžů, trilobitů a dalších skupin. Směrem do nadloží tato poloha přechází do přibližně $10 \mathrm{~cm}$ mocného šedého vápence (obr. 3, poloha $\mathrm{C}$ ) s četnými trilobity a další faunou (mlži, klymenie, ortokonní nautiloidi). Výše spočívá cca $5 \mathrm{~cm}$ mocná poloha tvořená rezavým a bílým sparitickým kalcitem nebo případně dolomitem, ve které je místy patrná bioturbace. Nad ní je vyvinuta poloha jílovitého vápence (obr. 3 , poloha $\mathrm{D}$ ) s trilobity, mlži a cephalopody, která představuje stratigraficky nejmladší polohu zmíněného intervalu s hojnou makrofaunou. Směrem do nadloží pokračuje sled šedých křtinských vápenců. 


\section{Konodontová biostratigrafie}

Konodontová fauna $\mathrm{z}$ báze profilu poskytla mj. konodonty Palmatolepis glabra lepta ZIEGLER - HUDDLE (pozdní morfotyp), Palmatolepis glabra distorta BRANSON - MEHL a Palmatolepis marginifera marginifera HELMS, kteří svědčí pro rozpětí zón spodní Palmatolepis marginifera až spodní Palmatolepis rugosa trachytera. Ze vzorku pocházejícího z polohy cca $10 \mathrm{~cm}$ pod čočkami černých vápenců annulata eventu lze zmínit taxony Palmatolepis glabra lepta (pozdní morfotyp), Palmatolepis minuta minuta BRANSON - MEHL, Palmatolepis rugosa trachytera ZIEGLER a Palmatolepis cf. glabra distorta, které dokládají zónu Palmatolepis rugosa trachytera. Další vzorek, který byl odebrán z čoček černých vápenců (obr. 3, poloha A), poskytl ze stratigraficky významnějších konodontů taxony Palmatolepis glabra lepta (pozdní morfotyp), Palmatolepis minuta minuta, Palmatolepis rugosa trachytera, Palmatolepis perlobata cf. grossi, Polygnathus homoirregularis ZIEGLER, Polygnathus cf. obliquicostatus a Pseudopolygnathus granulosus BRANSON - MEHL. Společenstvo náleží zóně svrchní Palmatolepis rugosa trachytera. Ve vzorku biodetritického vápence (obr. 3, poloha B) vyvinutého v nadloží černých čoček „klymeniových“ vápenců byl kromě jiných konodontových taxonů ojediněle přítomen Polygnathus styriacus ZIEGLER, který nastupuje na bázi zóny spodní Palmatolepis perlobata postera. Z nadložní polohy šedého vápence (obr. 3 , poloha $\mathrm{C}$ ) byly zjištěny konodontové taxony, které $\mathrm{z}$ hlediska detailní biostratigrafie nejsou př́liš informativní, nicméně tato poloha spadá pravděpodobně do rozpětí zón spodní až svrchní Palmatolepis perlobata postera. Z polohy jílovitého vápence (obr. 3, poloha D) byly získány pouze 2 platformní elementy Palmatolepis sp. Z nejvyšší polohy v profilu byly determinovány taxony Palmatolepis perlobata postera ZIEGLER (morfotyp 1), Palmatolepis rugosa cf. rugosa, Pseudopolygnathus brevipennatus ZIEGLER, Pseudopolygnathus controversus SANDBERG - ZIEGLER (morfotyp 2) a Polygnathus obliquicostatus ZIEGLER. Přítomnost zmíněných taxonů umožňuje zařazení do rozpětí nejvyšší části zóny svrchní Palmatolepis perlobata postera až nižší části zóny střední Palmatolepis gracilis expansa.

\section{Diskuze a závěr}

Taxony Palmatolepis glabra lepta (pozdní morfotyp), Palmatolepis minuta minuta a Palmatolepis rugosa trachyterav poloze čoček černých vápenců (obr. 3 , poloha $\mathrm{A}$ ) svědčí pro spodní annulata event (obr. 1). Ve spodním annulata eventu se podle Hartenfelse (2011) poprvé objevují některé konodontové taxony (např. Polygnathus homoirregularis) a zároveň do něj zasahují jiné taxony, které vymizí pod stratigrafickou úrovní svrchního annulata eventu (napr. Palmatolepis glabra lepta - pozdní morfotyp). Pro rozlišení svrchního annulata eventu však nelze obdobnou kombinaci posledních a prvních výskytů taxonů použít. Svrchní annulata event a stratigrafické úrovně odpovídající polohám „Wagnerbank“ či „Annulata“ limestone se nepodařilo na studovaném profilu jednoznačně rozlišit. Je však možné, že by tyto stratigrafické úrovně i báze zóny Palmatolepis perlobata postera mohly být kondenzovány $\mathrm{v}$ rámci polohy biodetritického vápence (obr. 3, poloha $\mathrm{B}$ ) do velmi malých mocností. Vyšší části intervalu s hojnou makrofaunou (obr. 3, polohy C, D) spadají již nad bázi zóny Palmatolepis perlobata postera a jsou tudíž stratigraficky mladší než fosiliferní polohy „Wagnerbank“ a „Annulata“ limestone (obr. 1).

\section{Poděkování}

Poděkování patři Dr. Svenu Hartenfelsovi (Westfälische Wilhelms-Universität Münster, SRN) za konzultaci určení některých konodontových elementů, prof. Thomasi Ralphu Beckerovi (Westfälische Wilhelms-Universität Münster, SRN) za vyjádření $k$ makrofauně cephalopodì a v neposlední radě Bc. Hedvice Poukarové za poznámky k manuskriptu a za asistenci v terénu. Za pomoc v terénu patř́ poděkování též Tomáši Viktorýnovi. Recenzentům doc. Mgr. Ondřeji Bábkovi, Dr. a Mgr. Tomáši Kumpanovi děkujeme za podnětné připomínky $k$ textu. Tento výzkum byl financován z grantového projektu GAČR (P210/11/1891). 


\section{Literatura}

Becker, R. T. - House, M. R. (2000): Devonian ammonoid zones and their correlation with established series and stage boundaries. - Courier Forschungsinstitut Senckenberg, 220, 113-151.

Clausen, C.-D. - Korn, D. (2008): Hoheres Mitteldevon und Oberdevon des nördlichen Rheinischen Schiefergebirges (mit Velberter Sattel und Kellerwald). - In: Deutsche Stratigraphische Kommision: Stratigraphie von Deutschland VIII. Devon. - Schriftenreihe der Deutschen Gesellschaft für Geowissenschaften, 52, 439-481.

Dvořák, J. - Friáková, O. - Kullmann, J. (1988): Influence of Volcanism on Upper Devonian Black Limestone and Shale Deposition, Czechoslovakia. - In: McMillan, N. J. - Embry, A. F. - Glass, D. J. (eds): Devonian of the World. - Canadian Society of Petroleum Geologists, Memoir, 14, 2, 393-398.

Hartenfels, S. (2011): Die globalen Annulata-Events und die Dasberg-Krise (Famennium, Oberdevon) in Europa und Nord-Afrika - hochauflösende Conodonten-Stratigraphie, Karbonat-Mikrofazies, Paläoökologie und Paläodiversität. - Münstersche Forschungen zur Geologie und Paläontologie, 105, 17-527.

House, M. R. (2002): Strength, timing, setting and cause of mid-Palaeozoic extinctions. - Palaeogeography, Palaeoclimatology, Palaeoecology, 181, 5-25.

Chlupáč, I. (1966): Nové nálezy klymenií ve svrchním devonu Moravského krasu. - Věstník Ústředního ústavu geologického, 41, 93-98.

Joachimski, M. M. - Breisig, S. - Buggisch, W. - Talent, J. A. - Mawson, R. - Gereke, M. - Morrow, J. R. - Day, J. - Weddige, K. (2009): Devonian climate and reef evolution: insights from oxygen isotopes in apatite. Earth and Planetary Science Letters, 284, 3-4, 599-609.

Korn, D. (2004): The mid-Famennian ammonoid succession in the Rhenish Mountains: the "annulata Event" reconsidered. Geological Quarterly, 48, 245-252.

Korn, D. - Ziegler, W. (2002): The ammonoid and conodont zonation at Enkenberg (Famennian, Late Devonian; Rhenish Mountains). - Senckenbergiana lethaea, 82, 2, 453-462.

Raczka, M. - Marynowski, L. - Filipiak, P. - Sobstel, M. - Pisarzowska, A. - Bond, D. P. G. (2010): Anoxic Annulata events in the Late Famennian of the Holy Cross Mountains (Southern Poland): Geochemical and palaeontological record. - Palaeogeography, Palaeoclimatology, Palaeoecology, 297, 549-575.

Rzehak, A. (1910): Der Brüner Clymenienkalk. - Zeitschrift des Mährischen Landesmuseums, 10, 149-216.

Sandberg, C. A. - Morrow, J. R. - Ziegler, W. (2002): Late Devonian sea-level changes, catastrophic events, and mass extinctions. - In: Koeberl, C. - MacLeod, K. G. (eds): Catastrophic Events and Mass Extinctions: Impacts and Beyond. - Geological Society of America, Special Papers, 356, 473-487.

Walliser, O. H. (1996): Global events in the Devonian and Carboniferous. - In: Walliser O. H. (ed.): Global Events and Event Stratigraphy, 225-250, Springer.

Ziegler, W. - Sandberg, C. A. (1984): Palmatolepis-based revision of upper part of standard Late Devonian conodont zonation. In: Clark, D. L.: Conodont Biofacies and Provincialism. - Geological Society of America, Special Papers, 179-194. 